Synthesis of Hyperbranched Poly(arylene ether) from Monomer

\title{
Containing Nitro Group: Kinetically Controlled Growth of Polymer Chain through Dynamic Exchange of End Functional Groups
}

\author{
Yun Jun Kim, ${ }^{\dagger}$ Masa-aki Kakimoto, ${ }^{\dagger}$ and Sang Youl Kim ${ }^{*} \dagger$ \\ Department of Chemistry and School of Molecular Science (BK21), \\ Korea Advanced Institute of Science and Technology (KAIST), \\ 373-1, Guseong-Dong, Yuseong-Gu, Daejeon 305-701, Korea, \\ and Department of Organic \& Polymeric Materials, \\ Tokyo Institute of Technology, \\ 2-12-1, O-okayama, Meguro-ku, Tokyo 152-8550, Japan
}

\section{Supporting Information}

\footnotetext{
${ }^{\dagger}$ Korea Advanced Institute of Science and Technology (KAIST).

$\$$ Tokyo Institute of Technology.

* To whom correspondence should be addressed: Tel 82-42-869-2834; Fax 82-42-869-2810; email kimsy@kaist.ac.kr
} 


\section{Experimental}

Materials. 5-Fluoro-2-nitrobenzotrifluoride (Aldrich) and 1,1,1-tris(4hydroxyphenyl)ethane (Aldrich) were used as received. Potassium carbonate $\left(\mathrm{K}_{2} \mathrm{CO}_{3}\right)$ was dried in vacuo at $150{ }^{\circ} \mathrm{C}$ for $24 \mathrm{~h}$ prior to use. Dimethyl sulfoxide (DMSO) was stirred in the presence of calcium hydride overnight and then distilled under reduced pressure. Toluene was stirred in the presence of calcium hydride overnight and then distilled under nitrogen. Phenol and $m$-cresol were distilled under reduced pressure. 2-Nitrobenzotrifluoride was recrystallized from methanol/hexane. Other commercially available reagent grade chemicals were used without further purification.

General measurement. FTIR spectra of the compounds were obtained with a Bruker EQUINOX-55 spectrophotometer using $\mathrm{KBr}$ pellet or $\mathrm{NaCl}$ plate. ${ }^{1} \mathrm{H} \mathrm{NMR}$ and ${ }^{13} \mathrm{C} \mathrm{NMR}$ spectra of the synthesized compounds were recorded on Bruker Fourier Transform AVANCE $400\left(400.13 \mathrm{MHz}\right.$ for ${ }^{1} \mathrm{H}$ and $100.62 \mathrm{MHz}$ for $\left.{ }^{13} \mathrm{C}\right)$ spectrometers. Chemical shift of NMR was reported in part per million ( $\mathrm{ppm})$ using tetramethylsilane as an internal reference. Splitting patterns designated as s (singlet), $\mathrm{d}$ (doublet), $\mathrm{t}$ (triplet), q (quartet), dd (doublets of doublet), m (multiplet), and br (broaden). Fast atom bombardment high-resolution mass (FAB HRMS) spectrum of the synthesized $\mathrm{A}_{2} \mathrm{C}$ type monomer (1) was obtained with a Jeol JMS-HX/HX 110A tandem mass spectrometer using 3-nitrobenzyl alcohol/sodium iodide (NBA/NaI) as a matrix. Electron impact high-resolution mass (EI HRMS) spectrum of the synthesized model compound (M1) was obtained with a Micromass Autospec Ultima mass spectrometer. Inherent viscosity data were obtained in $N, N$-dimethylacetamide with a Canon-Ubbelohde type viscometer at $30{ }^{\circ} \mathrm{C}$. Gel Permeation Chromatography (GPC) traces were obtained with a UV $(\lambda=270 \mathrm{~nm}$ ) or RI detector and packing columns (Waters Styragel HR 4, HR 5, and HR 
5E Columns, $7.8 \times 300 \mathrm{~mm}$ for each) using $N, N$-dimethylformamide containing $0.01 \mathrm{~mol} / \mathrm{L}$ of lithium bromides as an eluent at $40{ }^{\circ} \mathrm{C}$. Number $\left(M_{\mathrm{n}}\right)$ and weight $\left(M_{\mathrm{w}}\right)$ average molecular weights of the polymers were calculated on the basis of polystyrene standards. Differential scanning calorimetry (DSC) and thermogravimetric analysis (TGA) were performed on a TA 2200 thermal analyzer system. Melting point (m.p.) of the synthesized monomer and glass transition temperatures $\left(T_{\mathrm{g}}\right.$ 's) of the polymers were obtained with DSC instrument at a heating rate of $10{ }^{\circ} \mathrm{C} / \mathrm{min}$ in $\mathrm{N}_{2}$. TGA measurements were made at a heating rate of $10{ }^{\circ} \mathrm{C} / \mathrm{min}$ in air. The refractive indices were measured with a SPA-4000 prism coupler having two laser sources at $1310 \mathrm{~nm}$ and $632.8 \mathrm{~nm}$. About $4 \mu \mathrm{m}$ thick films were prepared on silicon substrates by spin-coating from cyclohexanone solutions (30 wt \%) of the synthesized polymers. The refractive index $(n)$ of the films was measured in transverse electric (TE) and transverse magnetic (TM) modes by choosing the appropriate polarization of the incident laser beam, giving the in-plane refractive index $\left(n_{\mathrm{TE}}=n_{\mathrm{xy}}\right)$ and the out-of-plane refractive index $\left(n_{\mathrm{TM}}=n_{\mathrm{z}}\right)$, respectively.

Synthesis and purification of $\mathbf{A}_{2} \mathbf{C}$ type monomer (1). The reaction was carried out under dry nitrogen atmosphere. 5-Fluoro-2-nitrobenzotrifluoride (3.000 g, $14.35 \mathrm{mmol}), 1,1,1$ tris(4-hydroxyphenyl)ethane (4.395 g, $14.35 \mathrm{mmol}), \mathrm{K}_{2} \mathrm{CO}_{3}(2.181 \mathrm{~g}, 15.78 \mathrm{mmol})$, and 27 $\mathrm{mL}$ of DMSO were added to a $50 \mathrm{~mL}$ two-necked flask. The reaction mixture was stirred at 90 ${ }^{\circ} \mathrm{C}$ for $4 \mathrm{~h}$. After the reaction was complete, the reaction mixture was poured into $500 \mathrm{~mL}$ of distilled water acidified with small amount of acetic acid. The resulting precipitate (a mixture of four compounds) was filtered, washed with distilled water, and dried in vacuo. The mixture was poured into $100 \mathrm{~mL}$ of dichloromethane, and the insoluble compound (1,1,1-tris(4hydroxyphenyl)ethane) was filtered. $\mathrm{A}_{2} \mathrm{C}$ type monomer (1) was almost exclusively extracted from the filtrate with $2 \% \mathrm{NaOH}$ solution $(100 \mathrm{~mL} \times 3)$. After the basic aqueous layer was 
acidified with $12 \mathrm{~N} \mathrm{HCl}$ solution, the resulting suspension was extracted with pure dichloromethane $(200 \mathrm{~mL} \times 2)$ to give the pale yellow solid after the evaporation of the excess solvent. 1 was further purified by silica column chromatography using ethylacetate/n-hexane $(\mathrm{v} / \mathrm{v}=1 / 1)$ as an eluent, and then recrystallized from methanol/distilled water $(2.675 \mathrm{~g}, 37.6 \%$ yield).: m.p. 95-97 ${ }^{\circ}$ C. FTIR $\left(\mathrm{KBr}, \mathrm{cm}^{-1}\right)$ : $3419(\mathrm{O}-\mathrm{H})$; 3040, 2978 (aromatic and aliphatic C$\mathrm{H}) ; 1587,1504$ (aromatic C=C); 1537, $1356\left(\mathrm{NO}_{2}\right) ; 1236(\mathrm{C}-\mathrm{O}-\mathrm{C}) ; 1170-1110(\mathrm{C}-\mathrm{F}) .{ }^{1} \mathrm{H}$ NMR $\left(\mathrm{CDCl}_{3}, 400.13 \mathrm{MHz}, \mathrm{ppm}\right): 7.94(\mathrm{~d}, 1 \mathrm{H}, J=8.99 \mathrm{~Hz}) ; 7.38(\mathrm{~d}, 1 \mathrm{H}, J=2.64 \mathrm{~Hz}) ; 7.17-7.14$ (m, 3H); 6.96-6.94 (m, 6H); $6.74(\mathrm{dd}, 4 \mathrm{H}, J=6.65 \mathrm{~Hz}, J=2.16 \mathrm{~Hz}) ; 5.25-4.75(\mathrm{br}, 2 \mathrm{H}) ; 2.13$ (s, 3H). ${ }^{13} \mathrm{C} \mathrm{NMR}\left(\mathrm{CDCl}_{3}, 100.62 \mathrm{MHz}, \mathrm{ppm}\right): 161.45,153.61,151.97,147.47,141.89$, 141.17, 130.67, 129.75, 128.01, 126.28 (q, $J=34.4 \mathrm{~Hz}), 121.59$ (q, $J=273.7 \mathrm{~Hz}), 119.60$, 119.41, $116.78(\mathrm{q}, J=5.7 \mathrm{~Hz}), 114.75,50.94$, 30.74. FAB HRMS $(m / e)$ : calc. for $\mathrm{C}_{27} \mathrm{H}_{20} \mathrm{~F}_{3} \mathrm{NO}_{5} \mathrm{Na}\left(\mathrm{M}+\mathrm{Na}^{+}\right), 518.1191$; found, 518.1191.

\section{Fluorine displacement reaction of BC type monomer (5-fluoro-2-} nitrobenzotrifluoride) with $\mathbf{A}_{3}$ type monomer (1,1,1-tris(4-hydroxyphenyl)ethane). The reaction was carried out under dry nitrogen atmosphere. 5-Fluoro-2-nitrobenzotrifluoride (0.37990 g, $1.8168 \mathrm{mmol})$, 1,1,1-tris(4-hydroxyphenyl)ethane (0.55661 g, $1.8168 \mathrm{mmol})$, $\mathrm{K}_{2} \mathrm{CO}_{3}(0.25110 \mathrm{~g}, 1.8168 \mathrm{mmol})$, and $7.7 \mathrm{~mL}$ of DMSO were added to a $25 \mathrm{~mL}$ two-necked flask. The reaction mixture was stirred at $80{ }^{\circ} \mathrm{C}$ for $4 \mathrm{~h}$. Small portion of the reaction mixture was taken via syringe, added to DMSO- $d_{6}$, and analyzed by ${ }^{1} \mathrm{H}$ NMR spectroscopy to determine the ratio of the intermediates (The ${ }^{1} \mathrm{H}$ NMR spectrum of the crude mixture is shown in Figure S3.). All of the compounds were isolated from the remaining reaction mixture according to the work-up procedure described above. Finally, the compounds were further purified by silica column chromatography using ethylacetate/n-hexane $(\mathrm{v} / \mathrm{v}=1 / 1$ for the $\mathrm{A}_{3}$ and $\mathrm{A}_{2} \mathrm{C}$ type compounds; $\mathrm{v} / \mathrm{v}=1 / 2$ for the $\mathrm{AC}_{2}$ and $\mathrm{C}_{3}$ type compounds) as an eluent (The 
${ }^{1} \mathrm{H}$ NMR spectra of the isolated compounds are shown in Figure S4.).

Polymerizations. All the polymerization reactions were carried out under dry nitrogen atmosphere.

\section{Synthesis of $\mathrm{CF}_{3}$-HPAE1 through the selective and sequential $S_{N} A r$ reaction of $A_{3}$ and}

BC type monomers. A $50 \mathrm{~mL}$ three-necked flask was equipped with a mechanical stirrer and a Dean-Stark trap connected to a water-cooled condenser. 5-Fluoro-2-nitrobenzotrifluoride (1.0520 g, $5.0311 \mathrm{mmol})$, 1,1,1-tris(4-hydroxyphenyl)ethane (1.5413 g, $5.0311 \mathrm{mmol}), \mathrm{K}_{2} \mathrm{CO}_{3}$ (0.69535 $\mathrm{g}, 5.0311 \mathrm{mmol})$, and $21 \mathrm{~mL}$ of DMSO were added to the flask. The reaction mixture was stirred at $80{ }^{\circ} \mathrm{C}$ for $4 \mathrm{~h}$. After $\mathrm{K}_{2} \mathrm{CO}_{3}(1.0430 \mathrm{~g}, 7.5465 \mathrm{mmol})$ and $10 \mathrm{~mL}$ of toluene as an azeotroping reagent were added, the reaction mixture was heated to $135{ }^{\circ} \mathrm{C}$ for 3 $\mathrm{h}$ at which the toluene was brought to reflux. The toluene was periodically removed from the Dean-Stark trap, and dry toluene was added to the reaction mixture to ensure dehydration of the system. Then, the reaction mixture was stirred at $170{ }^{\circ} \mathrm{C}$ for $6 \mathrm{~h}$. The solution was poured into vigorously stirred distilled water, and then the mixture was acidified with small amount of acetic acid. The resulting polymer was filtered, washed with hot water, and dried in vacuo at $60{ }^{\circ} \mathrm{C}$. Further purification was carried out by dissolving the polymer in $20 \mathrm{~mL}$ of $\mathrm{N}, \mathrm{N}$ dimethylacetamide and precipitating it into vigorously stirred distilled water/methanol $(\mathrm{v} / \mathrm{v}=$ 1/1) mixture. The resulting polymer was filtered, washed with hot water and methanol repeatedly, and dried in vacuo at $60{ }^{\circ} \mathrm{C}(1.9651 \mathrm{~g}, 87.1 \%$ yield $) .: M_{\mathrm{w}}=1.55 \times 10^{5}(\mathrm{PDI}=$ 2.70 ), determined by GPC (RI detector) using polystyrene standards. $\eta_{\text {inh }}=0.21 \mathrm{dL} / \mathrm{g}$ with a concentration of $0.5 \mathrm{~g} / \mathrm{dL}$ in DMAc at $30{ }^{\circ} \mathrm{C}$. FTIR $\left(\mathrm{KBr}, \mathrm{cm}^{-1}\right): 3445(\mathrm{O}-\mathrm{H}) ; 3040,2979$ (aromatic and aliphatic C-H); 1606, 1489 (aromatic C=C); 1223 (C-O-C); 1170-1110 (C-F). ${ }^{1} \mathrm{H}$ NMR (DMSO- $\left.d_{6}, 400.13 \mathrm{MHz}, 100{ }^{\circ} \mathrm{C}, \mathrm{ppm}\right)$ : 9.2-8.3 (br, $\left.1 \mathrm{H}\right) ; 7.31(1 \mathrm{H}) ; 7.25(1 \mathrm{H}) ; 7.08$ (5H); $6.92(4 \mathrm{H}) ; 6.87(2 \mathrm{H}) ; 6.67(2 \mathrm{H}) ; 2.06(3 \mathrm{H})$. 
Molecular weight determination of growing polymeric chains. The above procedure was repeated with the following quantities of reagents: 5-Fluoro-2-nitrobenzotrifluoride (1.5329 g, $7.3309 \mathrm{mmol})$, 1,1,1-tris(4-hydroxyphenyl)ethane (2.2459 g, $7.3309 \mathrm{mmol}), \mathrm{K}_{2} \mathrm{CO}_{3}(1.0132 \mathrm{~g}$, $7.3309 \mathrm{mmol}$ for the fluorine displacement reaction at $80{ }^{\circ} \mathrm{C} ; 1.5198 \mathrm{~g}, 10.996 \mathrm{mmol}$ for the nitro displacement reaction at $170{ }^{\circ} \mathrm{C}$ ), $31 \mathrm{~mL}$ of DMSO, and $15 \mathrm{~mL}$ of toluene. Some of the reaction mixture was taken via syringe at a certain time interval $(2 \mathrm{~h}, 4 \mathrm{~h}$, and $6 \mathrm{~h})$ during the nitro displacement reaction. Each reaction mixture was poured into vigorously stirred distilled water, and then acidified with small amount of acetic acid. The resulting polymer was filtered, washed with distilled water, and then dried in vacuo at $60{ }^{\circ} \mathrm{C}$. (The GPC traces and molecular weight data of the polymer samples are shown in Figure S5).

\section{Synthesis of $\mathrm{CF}_{3}$-HPAE2 through the nitro displacement reaction of $\mathrm{A}_{2} \mathrm{C}$ type monomer.}

A $25 \mathrm{~mL}$ three-necked flask was equipped with a mechanical stirrer and a Dean-Stark trap connected to a water-cooled condenser. $1(0.60000 \mathrm{~g}, 1.2110 \mathrm{mmol}), \mathrm{K}_{2} \mathrm{CO}_{3}(0.25106 \mathrm{~g}$, $1.8165 \mathrm{mmol}), 4.9 \mathrm{~mL}$ of DMSO, and $2.5 \mathrm{~mL}$ of toluene were added to the flask. The reaction mixture was heated to $135{ }^{\circ} \mathrm{C}$ for $3 \mathrm{~h}$ at which the toluene was brought to reflux. The toluene was periodically removed from the Dean-Stark trap, and dry toluene was added to the reaction mixture to ensure dehydration of the system. Then, the reaction mixture was stirred at $170{ }^{\circ} \mathrm{C}$ for $6 \mathrm{~h}$. The solution was poured into vigorously stirred distilled water, and the mixture was acidified with small amount of acetic acid. The resulting polymer was filtered, washed with hot water, and dried in vacuo at $60{ }^{\circ} \mathrm{C}$. Further purification was carried out by dissolving the polymer in $5 \mathrm{~mL}$ of $\mathrm{N}, \mathrm{N}$-dimethylacetamide and precipitating it into vigorously stirred distilled water/methanol $(\mathrm{v} / \mathrm{v}=1 / 1)$ mixture. The resulting polymer was filtered, washed with hot water and methanol repeatedly, and dried in vacuo at $60{ }^{\circ} \mathrm{C}(0.4571 \mathrm{~g}, 84.2 \%$ yield $) .: \eta_{\text {inh }}$ 
$=0.24 \mathrm{dL} / \mathrm{g}$ with a concentration of $0.5 \mathrm{~g} / \mathrm{dL}$ in DMAc at $30{ }^{\circ} \mathrm{C}$. FTIR $\left(\mathrm{KBr}, \mathrm{cm}^{-1}\right): 3445(\mathrm{O}-$ H); 3039, 2978 (aromatic and aliphatic C-H); 1607, 1488 (aromatic C=C); 1223 (C-O-C); 1170-1110 (C-F). ${ }^{1} \mathrm{H}$ NMR (DMSO- $\left.d_{6}, 400.13 \mathrm{MHz}, 100{ }^{\circ} \mathrm{C}, \mathrm{ppm}\right): 9.2-8.3$ (br, $\left.1 \mathrm{H}\right) ; 7.30$ $(1 \mathrm{H}) ; 7.24(1 \mathrm{H}) ; 7.07(5 \mathrm{H}) ; 6.91(4 \mathrm{H}) ; 6.85(2 \mathrm{H}) ; 6.66(2 \mathrm{H}) ; 2.05(3 \mathrm{H})$. 


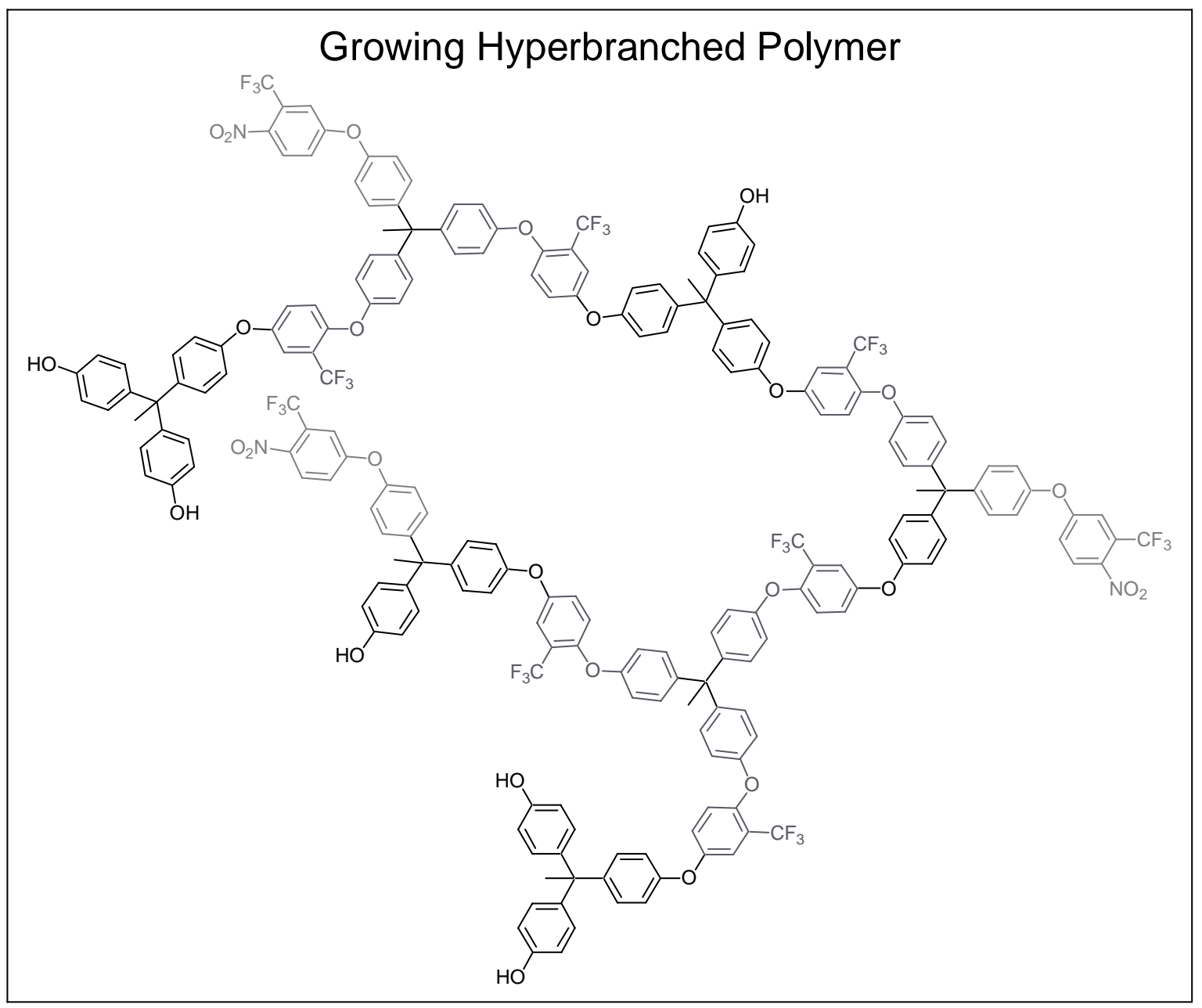

(1) In the main chain
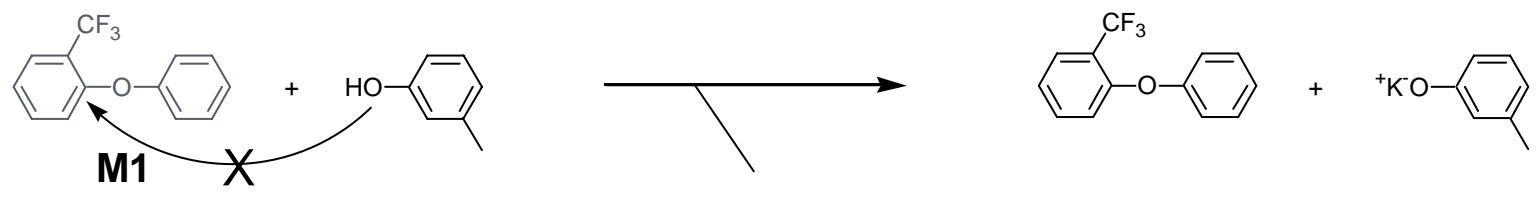

\section{Reaction Conditions}

(2) At the chain end

$\mathrm{K}_{2} \mathrm{CO}_{3}$, DMSO/toluene

150 or $170^{\circ} \mathrm{C}$
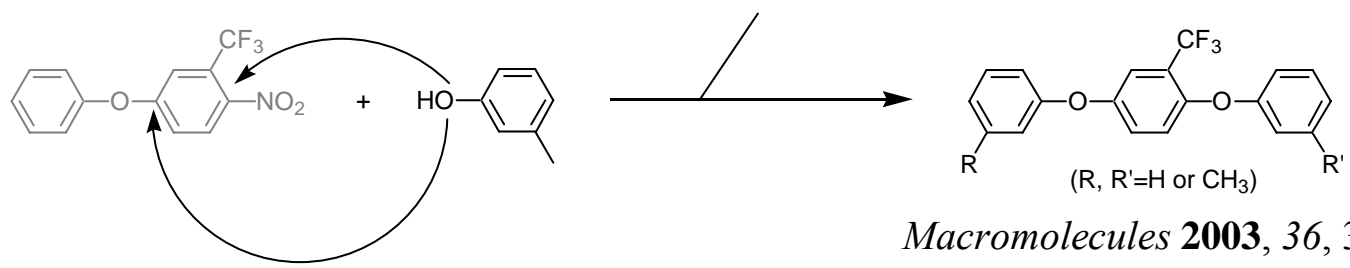

Macromolecules 2003, 36, 3809.

Scheme S1. Model Reactions to Monitor the Transetherification Site in the Growing Hyperbranched Polymers. 
Model Reactions. All model reactions were carried out under dry nitrogen atmosphere.

Synthesis of 2-trifluoromethyldiphenyl ether (M1). A $25 \mathrm{~mL}$ two-necked flask was equipped with a Dean-Stark trap connected to a water-cooled condenser. 2Nitrobenzotrifluoride $(0.6448 \mathrm{~g}, 3.374 \mathrm{mmol})$, phenol $(0.3175 \mathrm{~g}, 3.374 \mathrm{mmol}), \mathrm{K}_{2} \mathrm{CO}_{3}$ (0.6995 g, $5.061 \mathrm{mmol}), 3.5 \mathrm{~mL}$ of DMSO, and $2.0 \mathrm{~mL}$ of toluene were added to the flask. The reaction mixture was heated to $135^{\circ} \mathrm{C}$ for $4 \mathrm{~h}$ at which the toluene was brought to reflux. The toluene was periodically removed from the Dean-Stark trap, and fresh dry toluene was added to the reaction mixture to ensure dehydration of the system. Then, the reaction mixture was stirred at $150{ }^{\circ} \mathrm{C}$ for $12 \mathrm{~h}$. After the reaction was complete, the reaction mixture was poured into $50 \mathrm{~mL}$ of distilled water. The product was extracted with dichloromethane (20 $\mathrm{mL} \times 3)$, and washed with $2 \% \mathrm{NaOH}$ solution $(50 \mathrm{~mL} \times 1)$ and distilled water $(50 \mathrm{~mL} \times 2)$. After excess solvent was evaporated, the resulting pale yellow liquid was dried in vacuo at room temperature $\left(0.7702 \mathrm{~g}, 95.8 \%\right.$ yield).: FTIR $\left(\mathrm{NaCl}, \mathrm{cm}^{-1}\right): 3043$ (aromatic $\left.\mathrm{C}-\mathrm{H}\right) ; 1586,1488$ (aromatic C=C); 1246 (C-O-C); 1170-1110 (C-F). ${ }^{1} \mathrm{H}$ NMR (DMSO-d 6 , $\left.400.13 \mathrm{MHz}, \mathrm{ppm}\right)$ : $7.75(\mathrm{~d}, 1 \mathrm{H}, J=7.79 \mathrm{~Hz}) ; 7.61(\mathrm{t}, 1 \mathrm{H}, J=7.84 \mathrm{~Hz}) ; 7.41(\mathrm{t}, 2 \mathrm{H}, J=7.81 \mathrm{~Hz}) ; 7.29(\mathrm{t}, 1 \mathrm{H}, J=$ $7.63 \mathrm{~Hz}) ; 7.18(\mathrm{t}, 1 \mathrm{H}, J=7.69 \mathrm{~Hz}) ; 7.03(\mathrm{~d}, 2 \mathrm{H}, J=8.51 \mathrm{~Hz}) ; 6.99(\mathrm{~d}, 1 \mathrm{H}, J=8.24 \mathrm{~Hz}) .{ }^{13} \mathrm{C}$ NMR (DMSO- $\left.d_{6}, 100.62 \mathrm{MHz}, \mathrm{ppm}\right): 155.94,154.58,134.36,130.18,127.10$ (q, $\left.J=5.1 \mathrm{~Hz}\right)$, $124.23,123.43(\mathrm{q}, J=270.7 \mathrm{~Hz}), 123.41,119.80(\mathrm{q}, J=30.5 \mathrm{~Hz}), 119.35,118.88$. EI HRMS (m/e): calc. for $\mathrm{C}_{13} \mathrm{H}_{9} \mathrm{~F}_{3} \mathrm{O}, 238.0605$; found, 238.0605 .

Model reaction of M1 with $\boldsymbol{m}$-cresol. A $25 \mathrm{~mL}$ two-necked flask was equipped with a Dean-Stark trap connected to a water-cooled condenser. M1 $(0.1762 \mathrm{~g}, 0.7397 \mathrm{mmol}), \mathrm{m}$ cresol $(0.07999 \mathrm{~g}, 0.7397 \mathrm{mmol}), \mathrm{K}_{2} \mathrm{CO}_{3}(0.1534 \mathrm{~g}, 1.110 \mathrm{mmol}), 0.93 \mathrm{~mL}$ of DMSO, and $0.50 \mathrm{~mL}$ of toluene were added to the flask. The mixture was heated to $135{ }^{\circ} \mathrm{C}$ for $4 \mathrm{~h}$ at which the toluene was brought to reflux. The toluene was periodically removed from the 
Dean-Stark trap, and fresh dry toluene was added to the mixture to ensure dehydration of the system. Then, the temperature was raised to $150{ }^{\circ} \mathrm{C}$ or $170{ }^{\circ} \mathrm{C}$. After the mixture was stirred at each temperature for $6 \mathrm{~h}$, its small portion was taken via syringe, added to DMSO- $d_{6}$, and analyzed by ${ }^{1} \mathrm{H}$ NMR spectroscopy (The ${ }^{1} \mathrm{H}$ NMR spectra of the crude mixtures are shown in Figure S13.). 


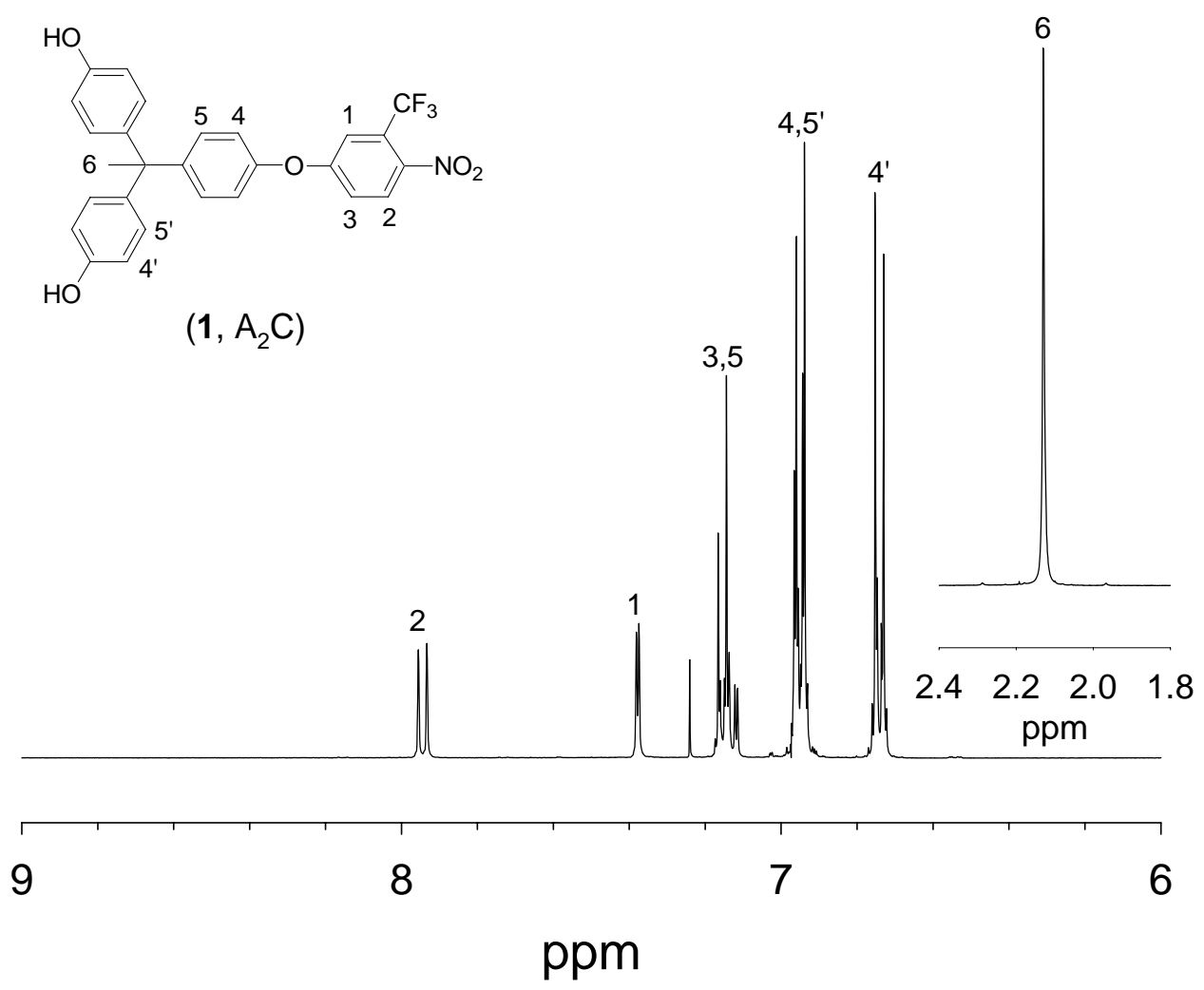

Figure S1. ${ }^{1} \mathrm{H}$ NMR spectrum of the synthesized $\mathrm{A}_{2} \mathrm{C}$ type monomer $\left(400 \mathrm{MHz}\right.$, in $\left.\mathrm{CDCl}_{3}\right)$.

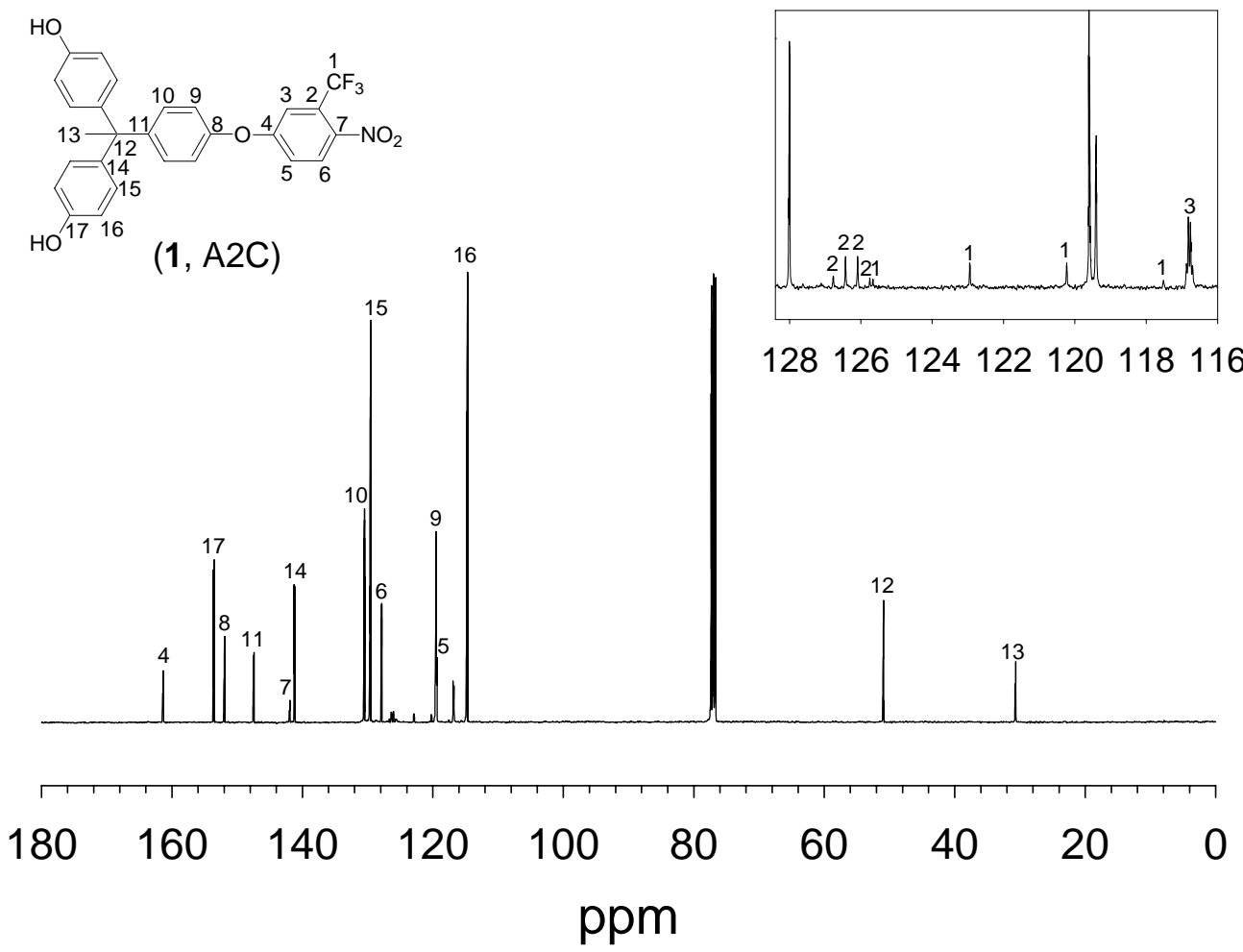

Figure S2. ${ }^{13} \mathrm{C}$ NMR spectrum of the synthesized $\mathrm{A}_{2} \mathrm{C}$ type monomer $\left(100 \mathrm{MHz}\right.$, in $\left.\mathrm{CDCl}_{3}\right)$. 

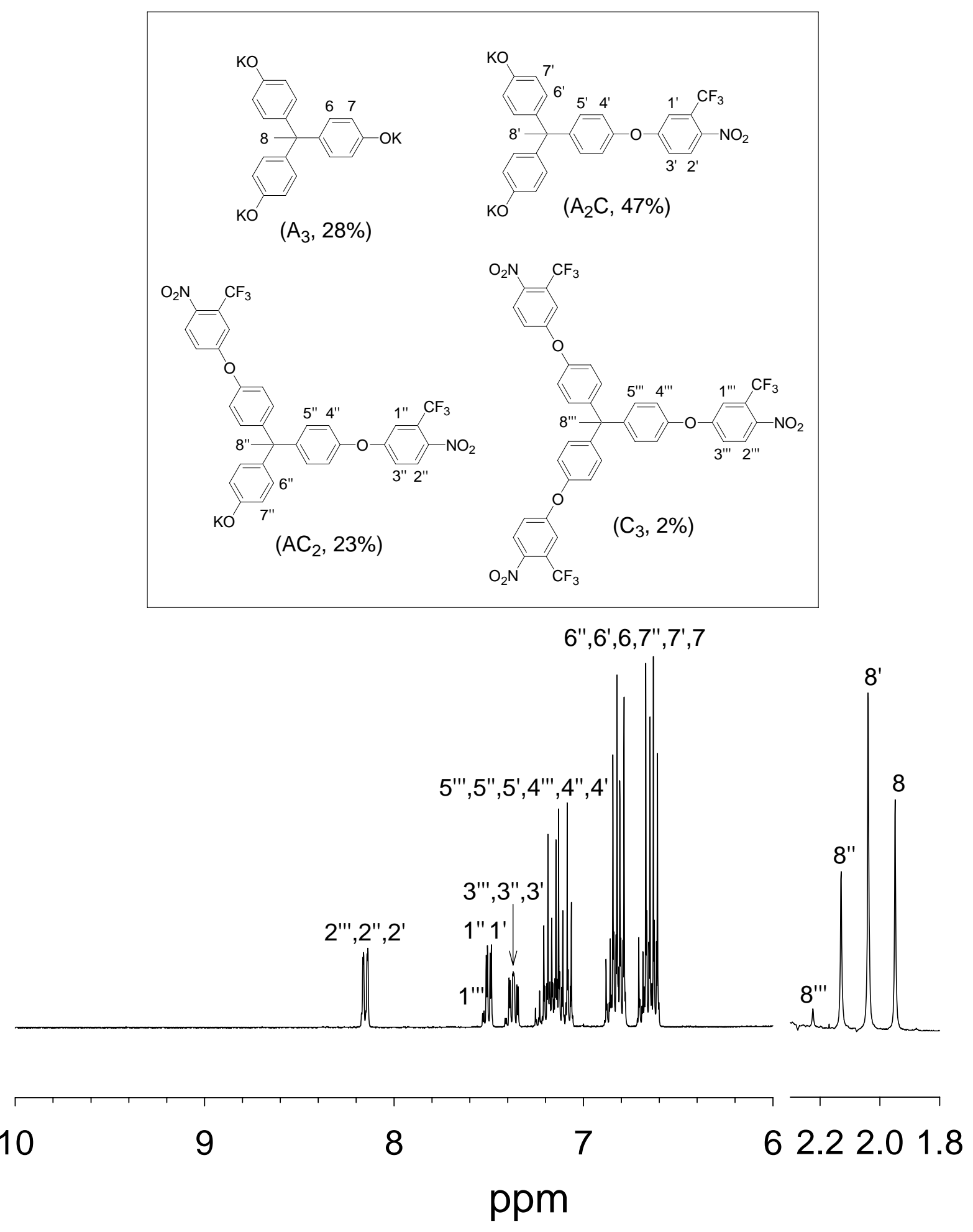

Figure S3. ${ }^{1} \mathrm{H}$ NMR spectrum of crude mixture after fluorine displacement reaction of 5fluoro-2-nitrobenzotrifluoride with 1,1,1-tris(4-hydroxyphenyl)ethane at $80{ }^{\circ} \mathrm{C}(400 \mathrm{MHz}$, in DMSO- $\left.d_{6}, 80^{\circ} \mathrm{C}\right)$. 

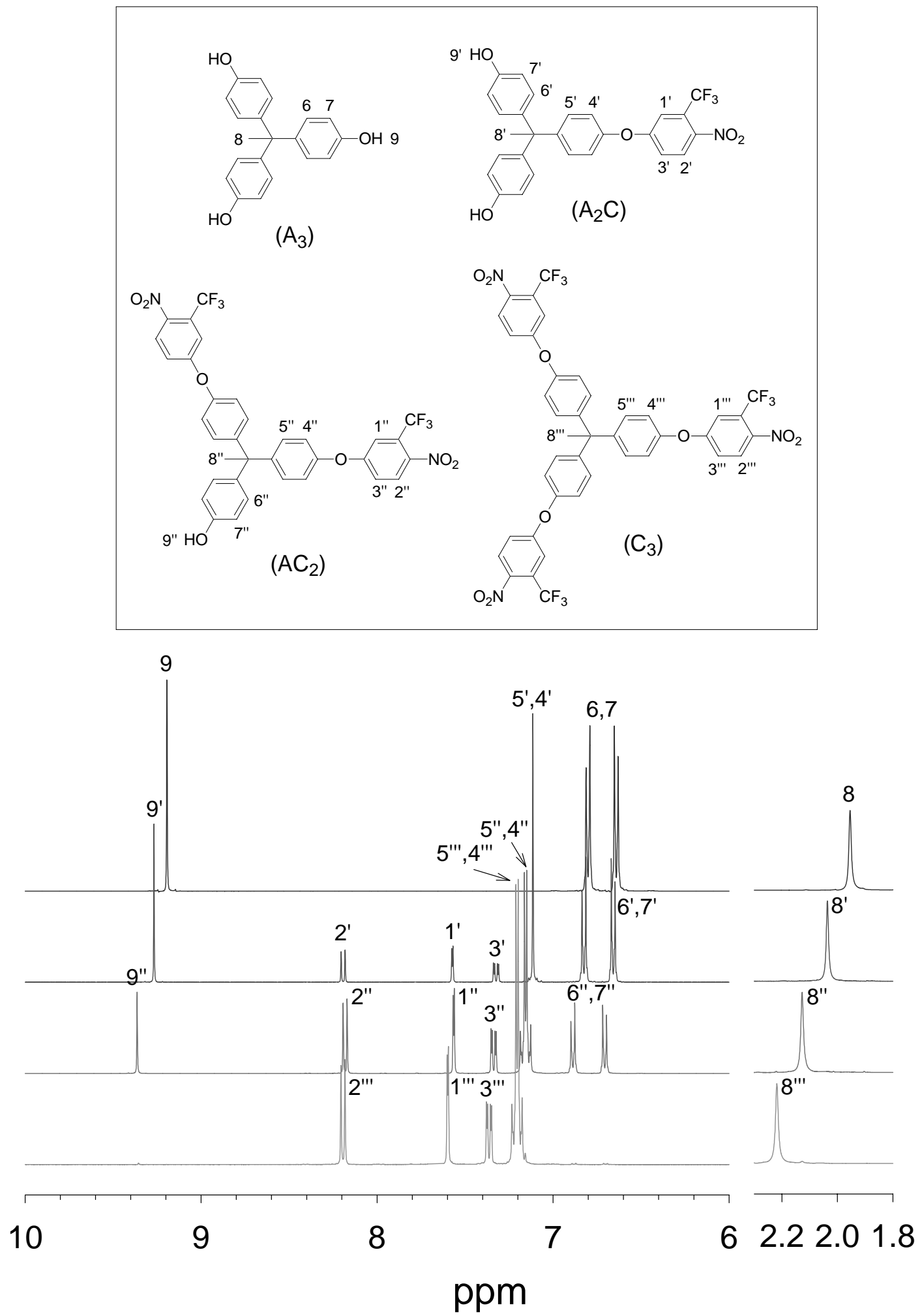

Figure S4. ${ }^{1} \mathrm{H}$ NMR spectrum of isolated compounds after fluorine displacement reaction of 5-fluoro-2-nitrobenzotrifluoride with 1,1,1-tris(4-hydroxyphenyl)ethane at $80{ }^{\circ} \mathrm{C}(400 \mathrm{MHz}$, in DMSO- $\left.d_{6}\right)$. 
(a)
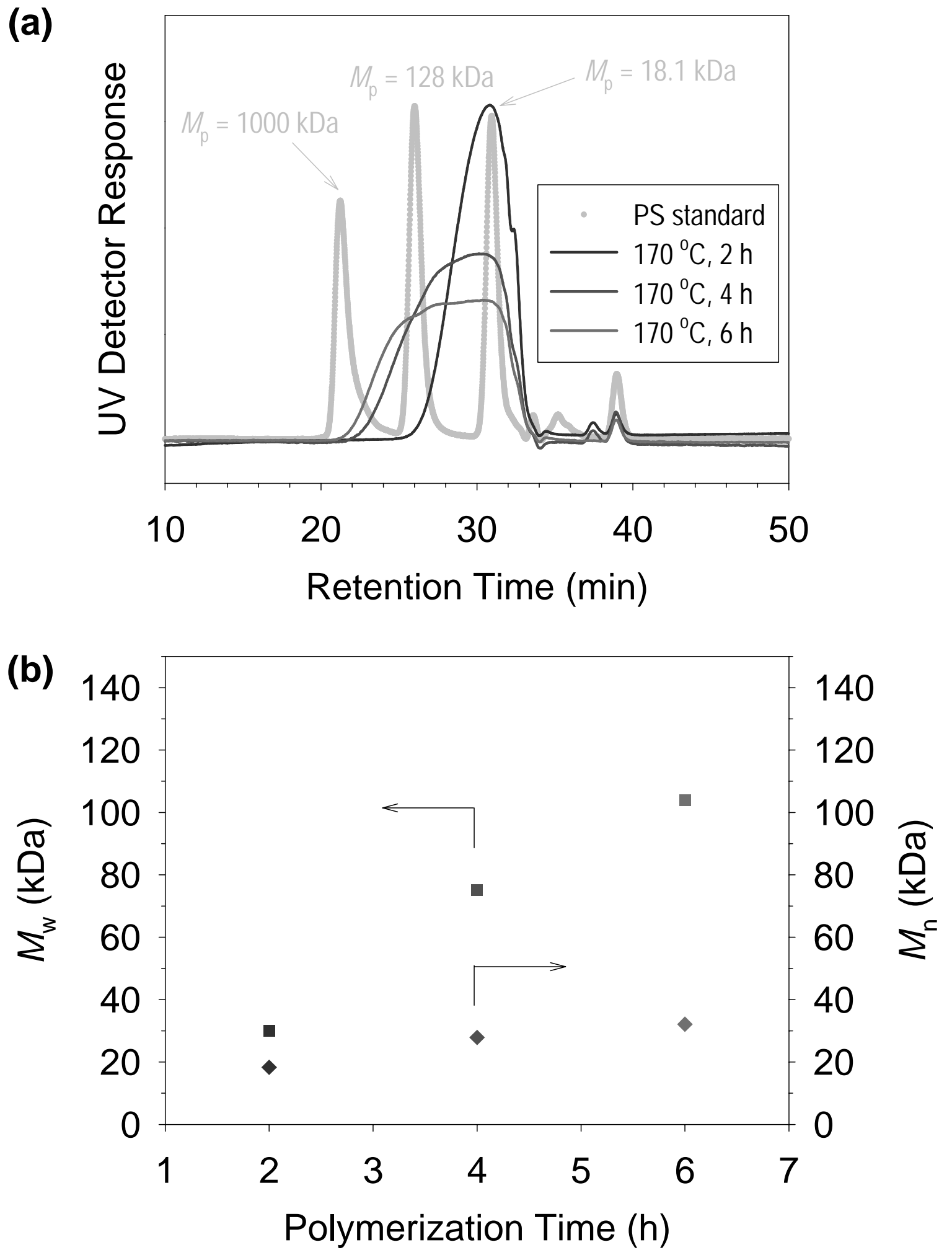

Figure S5. (a) GPC traces and (b) molecular weight data of growing polymeric chains during the nitro displacement reaction. 


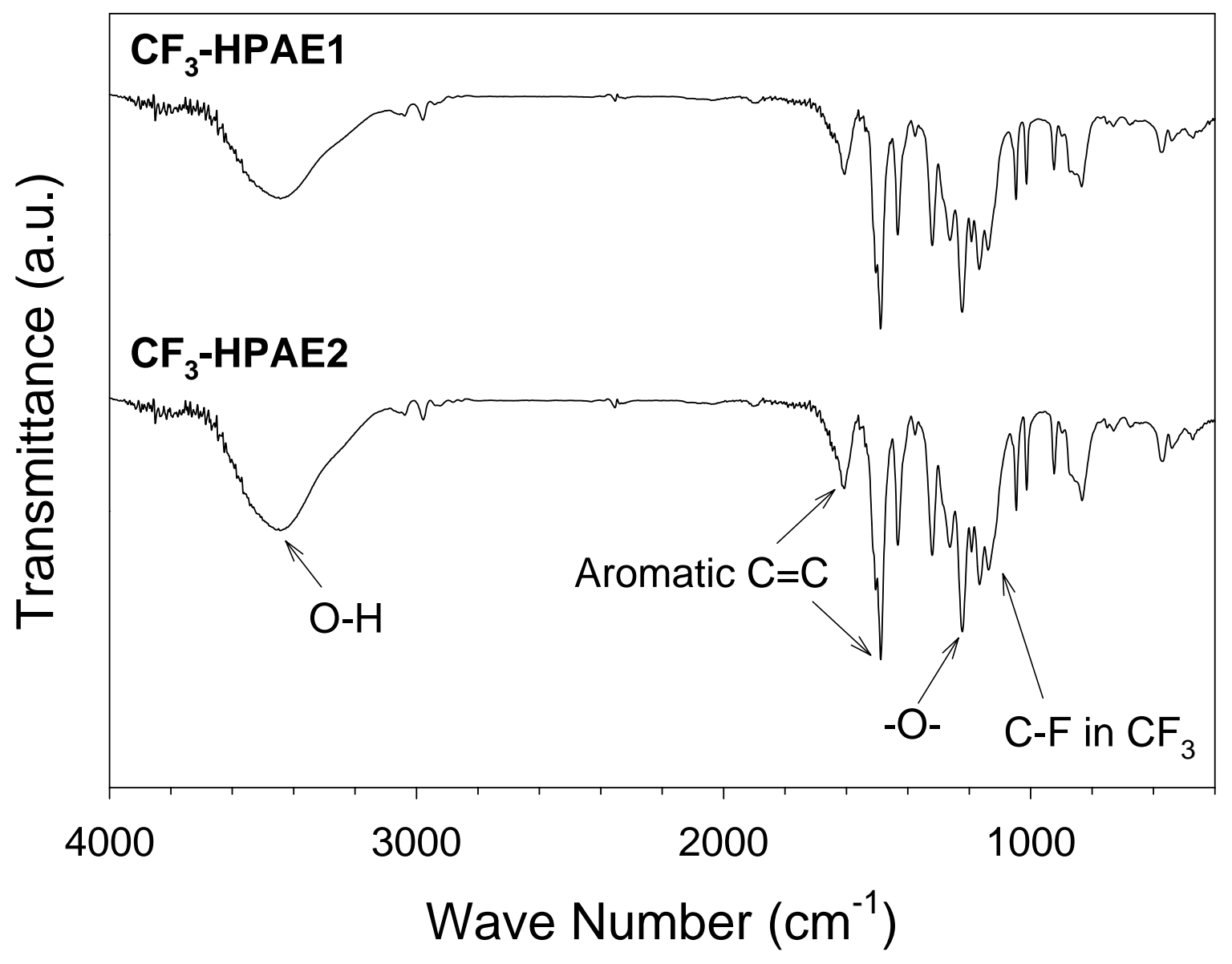

Figure S6. FTIR spectra of $\mathrm{CF}_{3}$-HPAE1 (top) and $\mathrm{CF}_{3}$-HPAE2 (bottom) ( $\mathrm{KBr}$ pellet). 

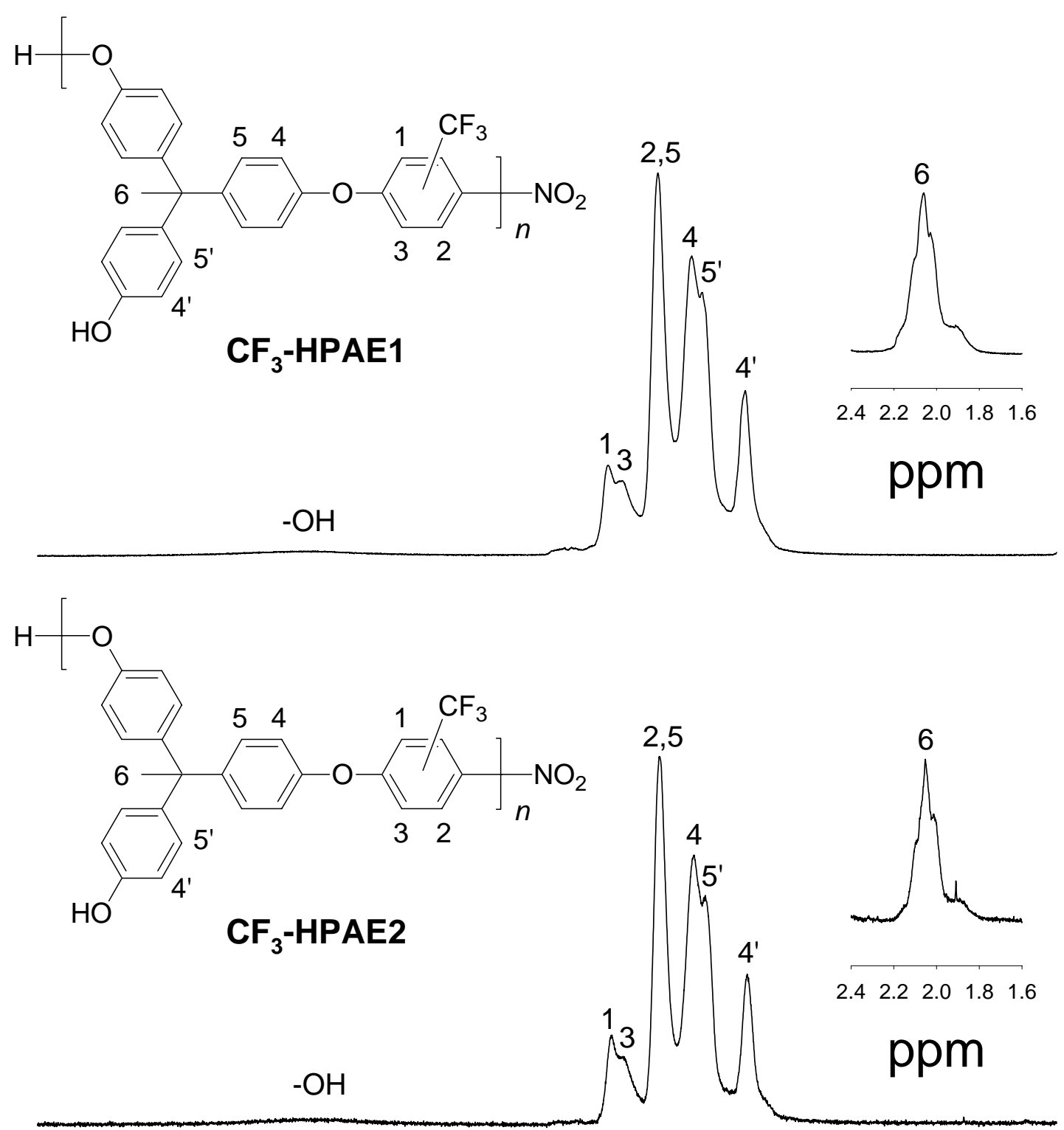

10

9

8

7

6

ppm

Figure S7. ${ }^{1} \mathrm{H}$ NMR spectra of $\mathrm{CF}_{3}$-HPAE1 (top) and $\mathrm{CF}_{3}$-HPAE2 (bottom) (400 MHz, in DMSO- $d_{6}, 100^{\circ} \mathrm{C}$ ). 


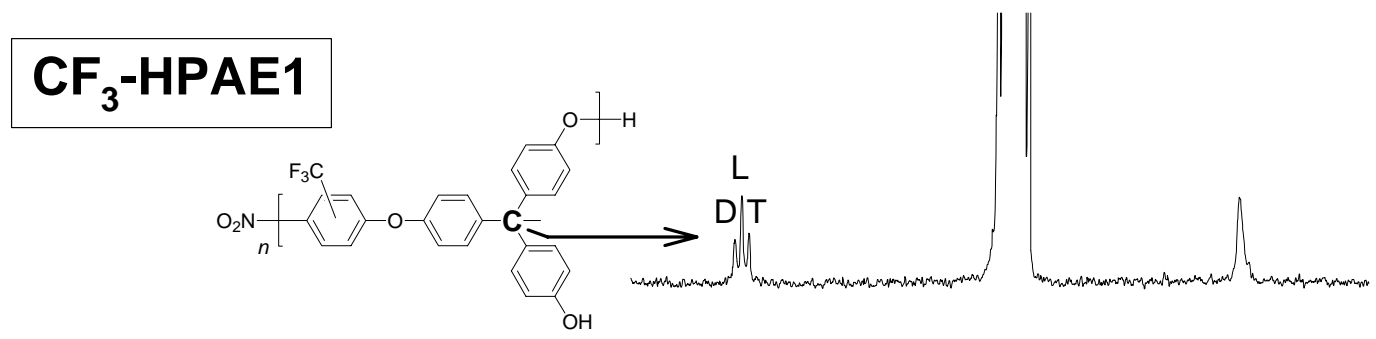

(a) $\mathrm{DB}=0.52$

(b) $\mathrm{DB}=0.52$
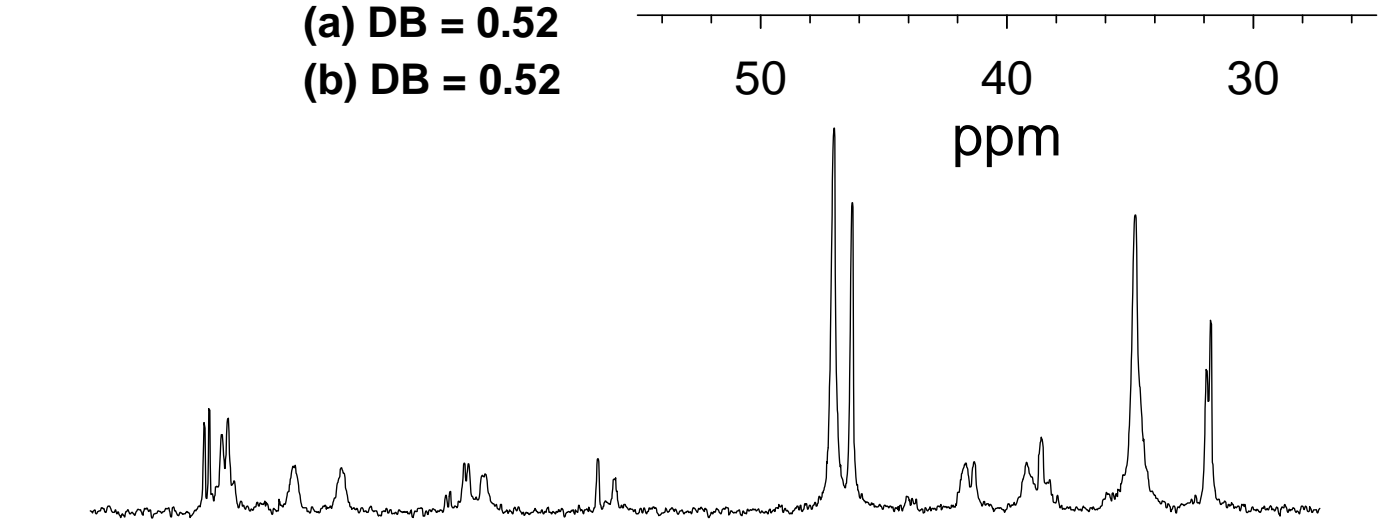

\section{$\mathrm{CF}_{3}$-HPAE2}
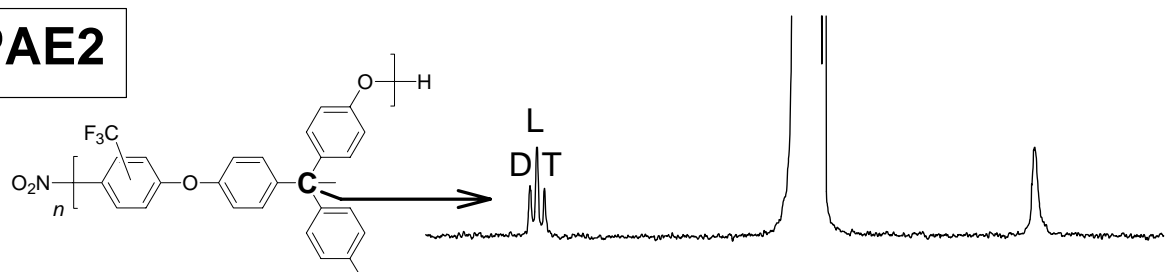

(a) $\mathrm{DB}=0.51$

(b) $\mathrm{DB}=0.53$

$\mathrm{OH}$

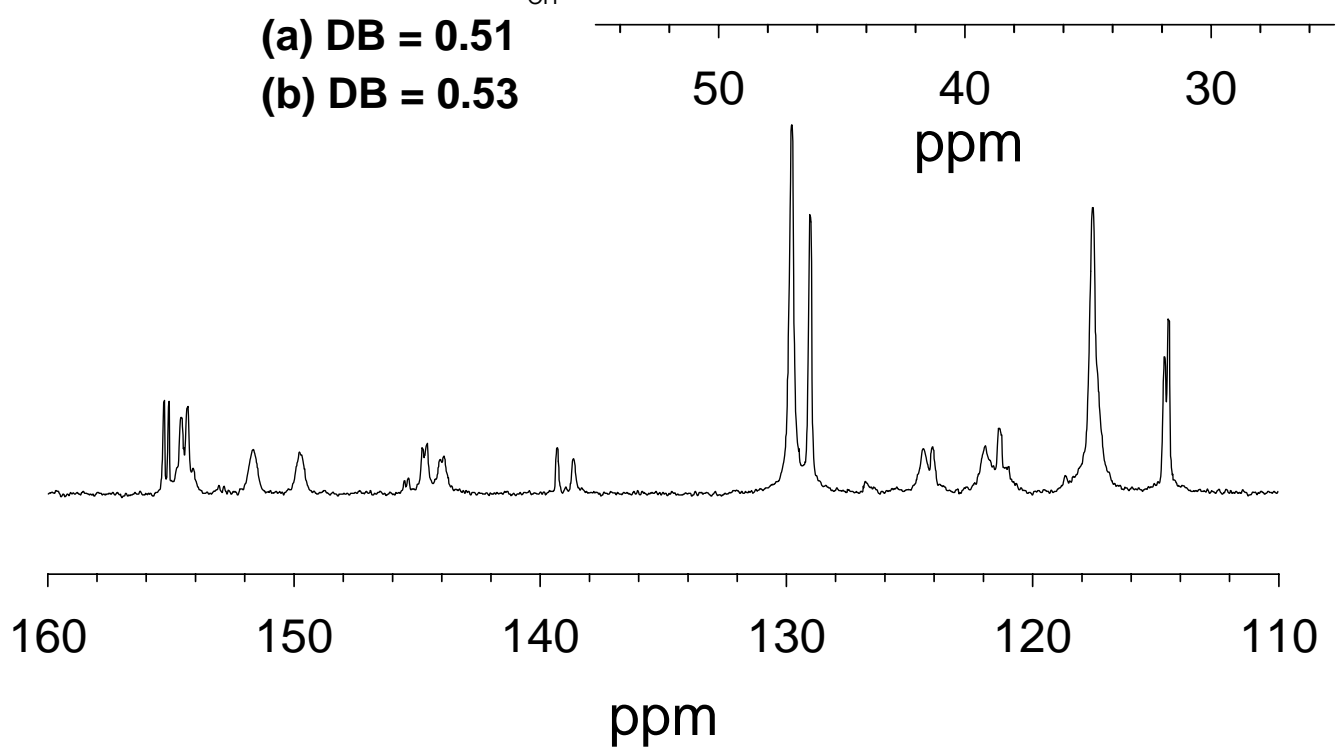

Figure S8. ${ }^{13} \mathrm{C}$ NMR spectra $\left(100 \mathrm{MHz}\right.$, in DMSO- $d_{6}$ ) of $\mathrm{CF}_{3}$-HPAE1 (top) and $\mathrm{CF}_{3}$-HPAE2 (bottom). The degree of branching (DB) was calculated according to the following equations: (a) $\mathrm{DB}=(\mathrm{D}+\mathrm{T}) /(\mathrm{D}+\mathrm{L}+\mathrm{T})^{1}$ and (b) $\mathrm{DB}=2 \mathrm{D} /(2 \mathrm{D}+\mathrm{L})^{2}$, where $\mathrm{D}, \mathrm{L}$, and $\mathrm{T}$ represent the numbers of dendritic, linear, and terminal units, respectively. 


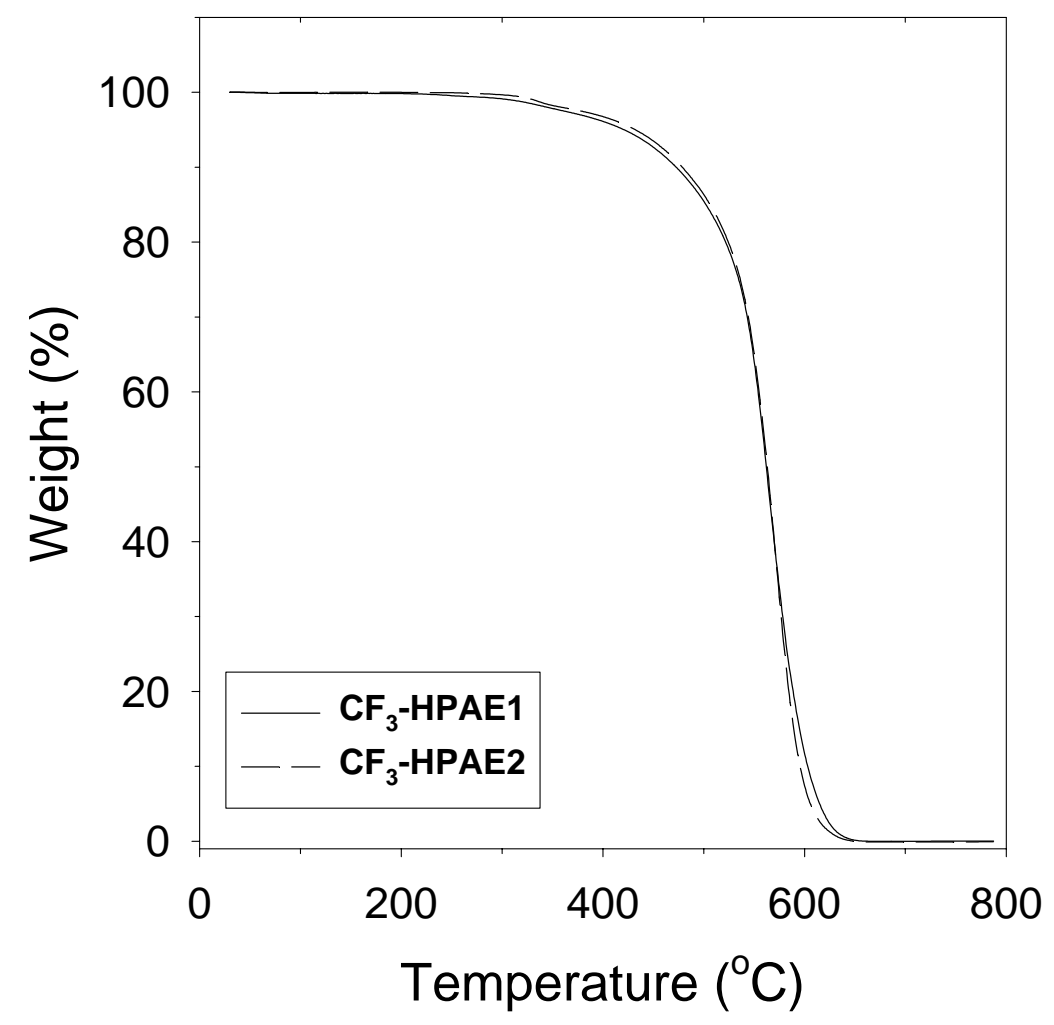

Figure S9. TGA curves of $\mathrm{CF}_{3}-\mathrm{HPAE} 1$ and $\mathrm{CF}_{3}-\mathrm{HPAE} 2$ in air (Heating rate: $10{ }^{\circ} \mathrm{C} / \mathrm{min}$ ).

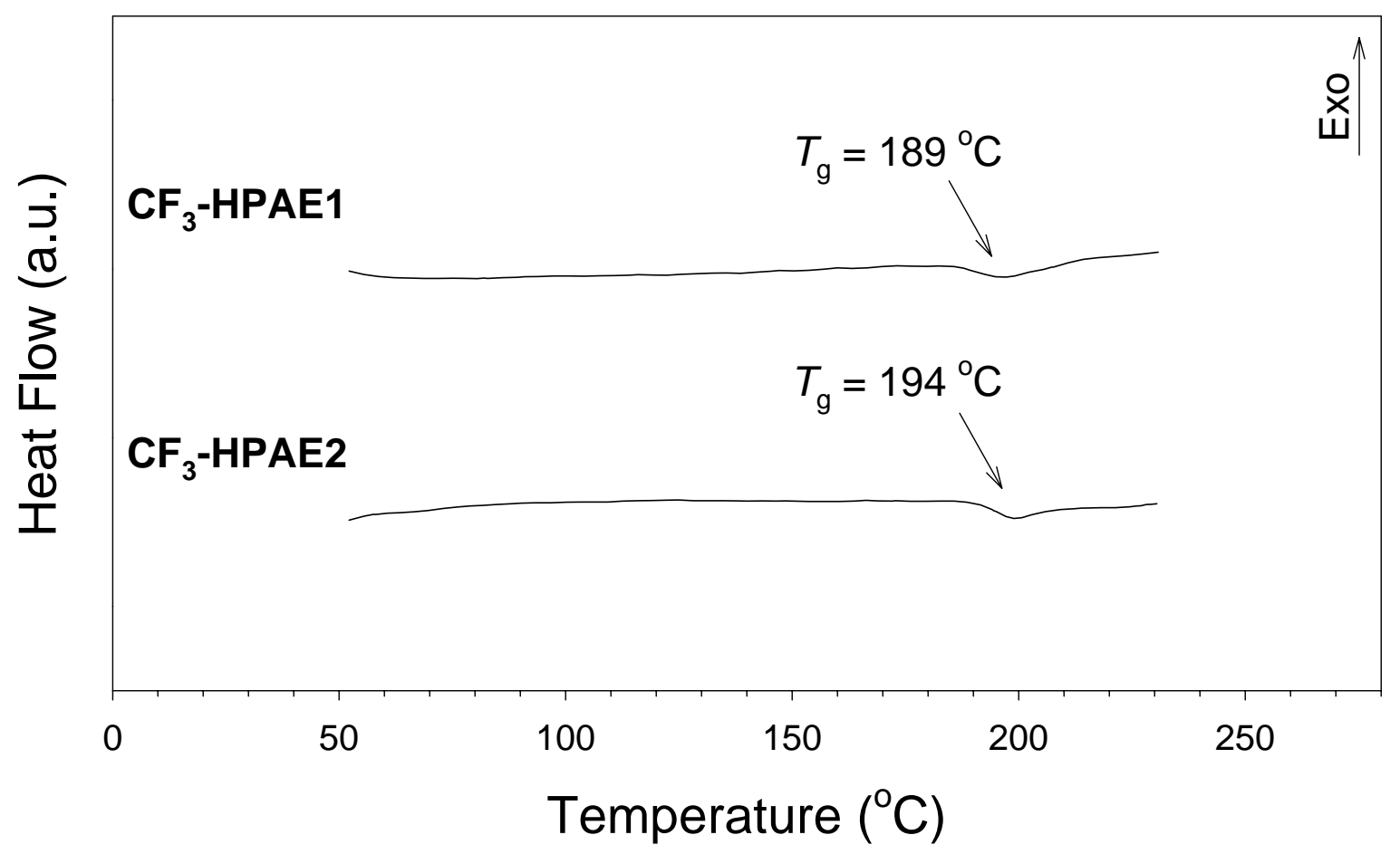

Figure S10. DSC curves of $\mathrm{CF}_{3}-\mathrm{HPAE} 1$ (top) and $\mathrm{CF}_{3}$-HPAE2 (bottom)

(Heating rate: $10^{\circ} \mathrm{C} / \mathrm{min}$ ). 
Table S1. Refractive Indices of $\mathrm{CF}_{3}$-HPAE1 and $\mathrm{CF}_{3}$-HPAE2

\begin{tabular}{cccccc}
\hline Wavelength (nm) & polymer & $n_{\mathrm{TE}}{ }^{a}$ & $n_{\mathrm{TM}}{ }^{b}$ & $n^{c}$ & $\Delta n^{d}$ \\
\hline \multirow{2}{*}{1310} & $\mathrm{CF}_{3}$-HPAE1 & 1.576 & 1.574 & 1.575 & 0.002 \\
\cline { 2 - 6 } & $\mathrm{CF}_{3}$-HPAE2 & 1.575 & 1.574 & 1.575 & 0.001 \\
\hline \multirow{2}{*}{632.8} & $\mathrm{CF}_{3}$-HPAE1 & 1.600 & 1.597 & 1.599 & 0.003 \\
\cline { 2 - 5 } & $\mathrm{CF}_{3}$-HPAE2 & 1.599 & 1.596 & 1.598 & 0.003 \\
\hline
\end{tabular}

${ }^{a}$ In-plane refractive index of polymer film.

${ }^{b}$ Out-of-plane refractive index of polymer film.

${ }^{c}$ Refractive index of polymer film: $\left(n_{\mathrm{TE}}\right.$ (in-plane refractive index) $+n_{\mathrm{TM}}$ (out-of-plane refractive index)) / 2 .

${ }^{d}$ Birefringence $=n_{\mathrm{TE}}-n_{\mathrm{TM}}$ 


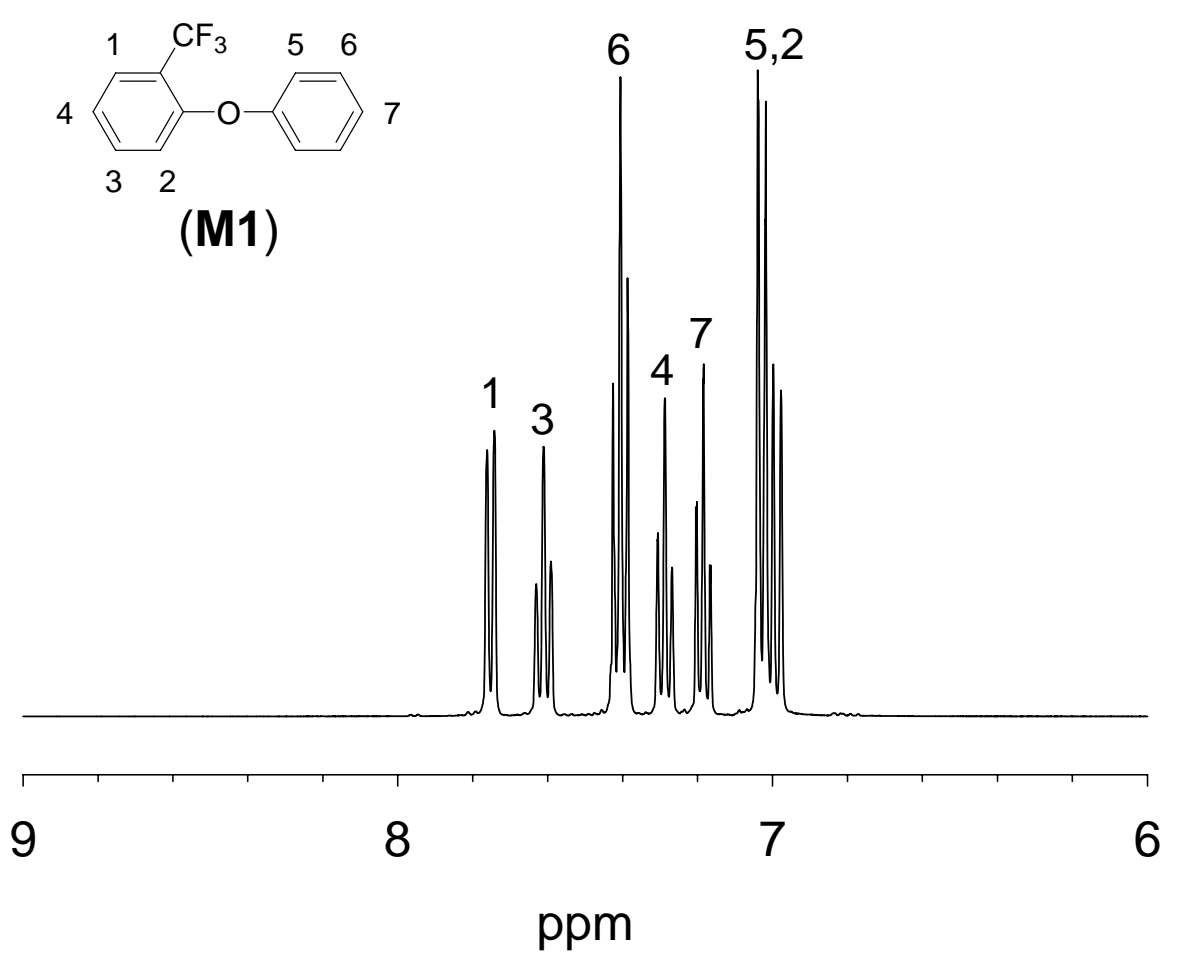

Figure S11. ${ }^{1} \mathrm{H}$ NMR spectrum of the model compound M1 (400 MHz, in DMSO- $\left.d_{6}\right)$.

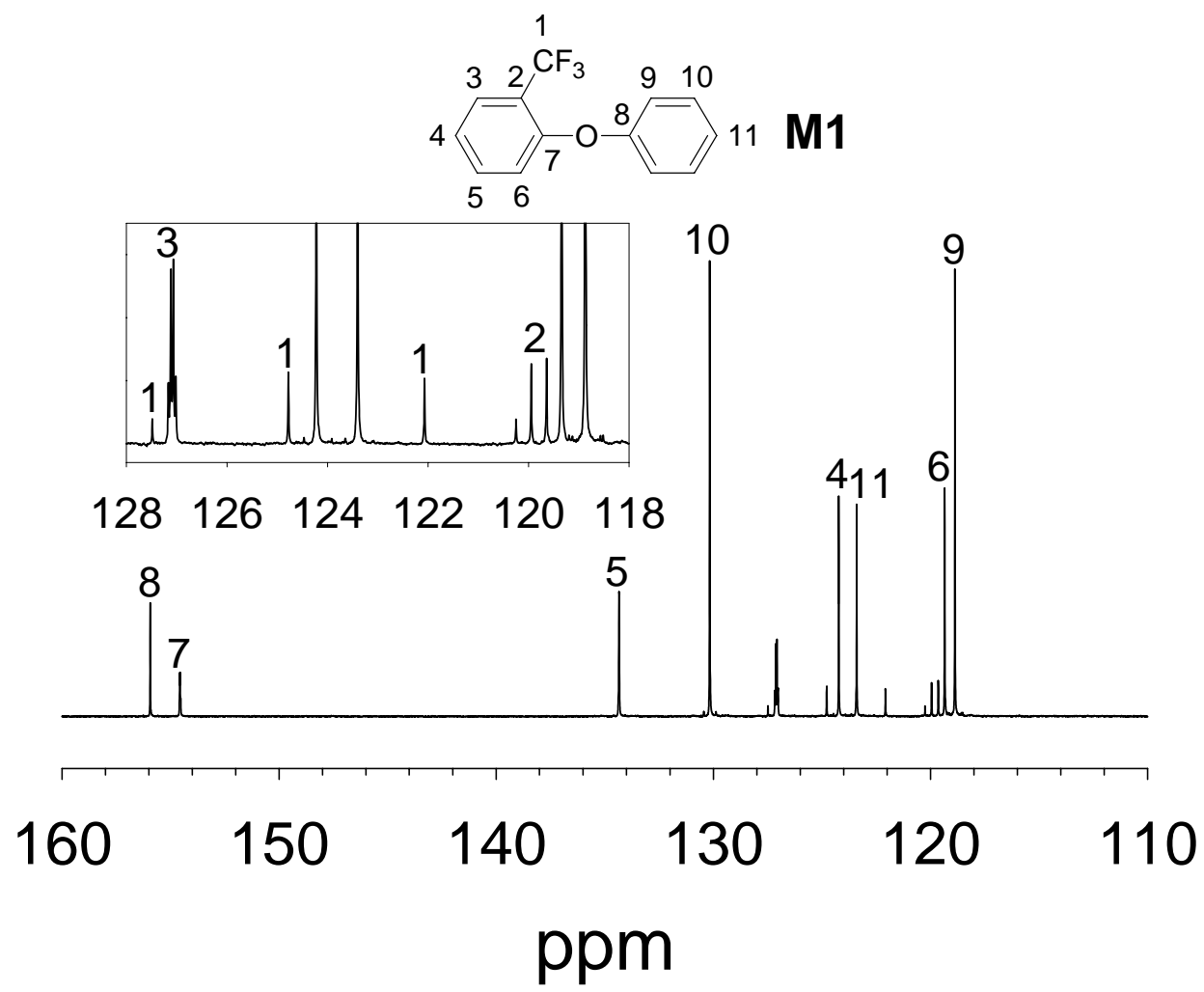

Figure S12. ${ }^{13} \mathrm{C}$ NMR spectrum of the model compound M1 $\left(100 \mathrm{MHz}\right.$, in DMSO- $\left.d_{6}\right)$. 


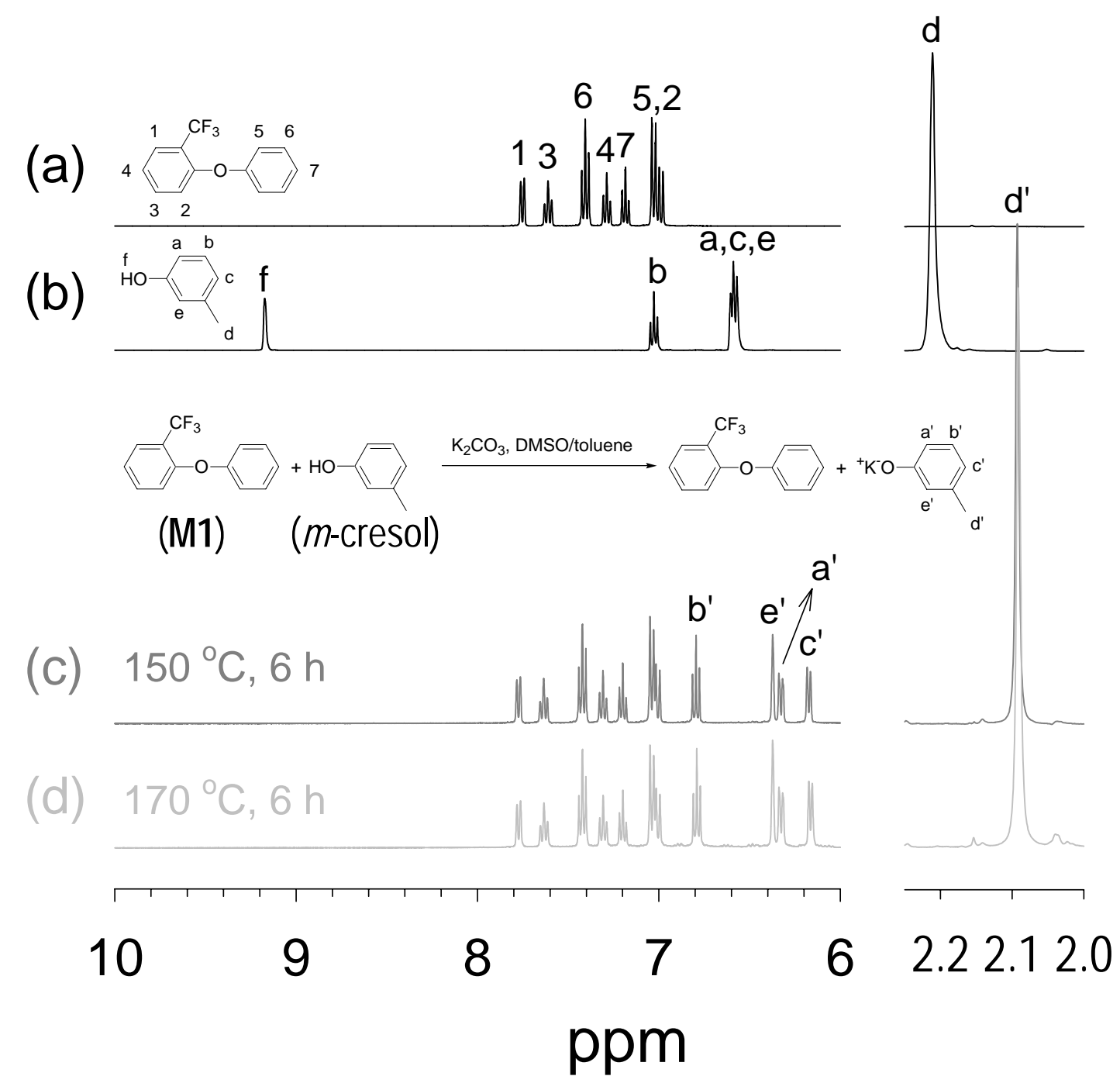

Figure S13. ${ }^{1} \mathrm{H}$ NMR spectra of (a) M1, (b) $m$-cresol, and (c)\&(d) crude mixture of the two compounds subjected to the heating in DMSO in the presence of $\mathrm{K}_{2} \mathrm{CO}_{3}(400 \mathrm{MHz}$, in $\left.\mathrm{DMSO}-d_{6}\right)$. 


\section{References}

(1) Hawker, C. J.; Lee, R.; Fréchet, J. M. J. J. Am. Chem. Soc. 1991, 113, 4583.

(2) Hölter, D.; Burgrath, A.; Frey, H. Acta Polym. 1997, 48, 30. 